\title{
Knowledge and Attitude towards the Introduction of Informatics to Nursing Training among Selected Nurse Educators/Leaders in Nigeria
}

\author{
B.L. Ajibade, Oladeji, M.O² ${ }^{2}$ Okunlade, J.O ${ }^{3}$ \\ Ladoke Akintola University of Technology, Ogbomosho, Oyo State, Department of Nursing, College of Health \\ Sciences, Isale-Osun, Osogbo, Osun State.Nigeria ${ }^{1,2,3}$.
}

\begin{abstract}
Background:- Technology in health care is increasingly becoming an integral part of the Nigeria health care delivery system and National Universities Commission has made it as part of bench-mark in the training of Nursing Students on Nursing informatics. Nursing and Midwifery Council is equally making efforts to see to the teaching and utilization of Nursing informatics by nursing students and practicing nurses. Therefore, this study was aimed at assessing the knowledge and attitude of nurse-educators and leaders on concept of nursing informatics.
\end{abstract}

Methods:- this was a descriptive study. The study was carried out among nurse, educators and leaders at the yearly Conference organized by the Nursing and Midwifery Council of Nigeria that place in Osogbo in April 2012. 175 respondents were randomly selected for the study out of 250 that registered for the conference. Only 150 returned their questionnaire and were used for the study. Three research questions were answered and three hypothesis were tested using Chi-square (x2) and correlation coefficient at 0.05 level of significance.

Results- One hundred and fifty (150) out of two hundred and fifty (250) respondents were used for the study $82.0 \%$ were females while $18.0 \%$ were males. $49.3 \%$ had Bsc/ BNSc, $36.0 \%$ had masters while $0.7 \%$ had Ph.D. $90.0 \%$ of respondents are knowledgeable. They all had positive attitude towards the introduction of informatics to the training of Nurses. There was no significant adherence in the attitude towards the introduction of informatics to nursing along gender attributes, there was no association between the qualifications and attitude of respondents towards the introduction of informatics to nursing and these was association between the respondents from different geo-political zones and their attitudes towards the introduction of informatics to nursing.

Conclusion- It was concluded that the regulating bodies for nursing practice and nursing education should ensure the implementation of curriculum on nursing informatics.

Key words: Knowledge, Attitude, Informatics, Nurse Educators/leader, Training.

\section{Introduction}

We live in the area of information technology(IT). Many health care organization have adopted policies forming the implementation of modern technology. Computers are used not only for diagnosis and imaging technique but also in home care and long term I. Since the development of the computer and the evolution of the internet, information technology has had a positive impact on health care delivery systems worldwide, particularly in the areas of disease control, diagnosis, patient management and teaching ${ }^{2-3}$. Nursing informatics is not a new specialty in nursing, however, many undergraduate schools are yet to incorporate this in their nursing curriculum ${ }^{3-4}$. Some authors ${ }^{5}$ define nursing informatics as "a combination of computer science, information science, and nursing science designed to assist in the management and processing of nursing data, information, and knowledge to support the practice of nursing-and delivery of nursing care. Nurses are engaged with information systems and different digital tools used for their clinical practice as a foundation for evidencebased care decision-support, and electronic health record. Unfortunately not all graduating (land current practicing nurses) are fully prepared to use these digital tools to support their practice ${ }^{5}$. In a study carried out among health care Professionals and medical students in a University teaching hospital on the attitude and utilization of computer, a total of 28 respondents $(18.9 \%)$ demonstrated a good knowledge of computer while $87(58.8 \%)$ of them had an average knowledge ${ }^{6}$ Oguntade and Ofibo ${ }^{4,7}$ discovered that $52 \%$ of the 250 students studied were aware of Medline on CD-ROM while only $24 \%$ had used it. Some researchers ${ }^{4}$ in Lagos reported that $80 \%$ of their final year medical and dental students had used the computer, but the use of soft-ware applications was very poor (19\%). A researcher ${ }^{5}$ found that only $42.6 \%$ of medical and nursing students could use a computer while about $60 \%$ had used internet. The introduction of technology and the internet into classrooms has been the most important change in the field education in the past 100 years. Both students and educators need time to reflect on this changing content and make the maximum advantage of IT9. It is important that nurses are able to demonstrate competence in the use of IT. It is necessary to acquire the basic skills in 
information technology that will allow them to progress through their educational programme. Nursing professionals have long recognized the importance of research evidence to practice ${ }^{12-15}$ while nurses' computer skill vary, the ability to locate relevant information in electronic database and the internet is crutial to modern practicce ${ }^{16-19}$. In a systematic review long and Turtle ${ }^{20}$ found that training with database had a positive impact on health professionals' information retrieval skills. This is a lack of knowledge about the skills of nurses working in Psychatric hospitals in using databases and the internet for information retrieval.

\section{Purpose of the study}

The purpose of the study was to describe:-

(1) Nurse Tutors/Educators' knowledge in information searches and the internet.

(2) Nurse Tutors/educators attitude in information Technology.

(3) differences in nurses information retrieval skill between different groups according to educators' genders, age, or job position.

\section{Population and data collection.}

\section{Methods}

The study was carried out in April, 2012 in Osogbo Osun State among director of nursing services, deputy director of nursing services, chief nurse tutors, assistant Chief nurse tutors and principal nurse tutors, during their yearly conference organized by the Nursing and Midwifery council of Nigeria is a regulating body for all practicing nurses in Nigeria.

\section{OBJECTIVES OF THE STUDY}

The Objectives of the study were to:

- $\quad$ Nurse, tutors/educators knowledge in Nursing informatics.

- $\quad$ assess the demographic data of the respondents.

- $\quad$ determine the attitude of respondents toward introduction of informatics to nursing training. determine the relationship between gender and the introduction of informatics to nursing training assess the relationship between respondents qualifications and attitude towards the introduction of informatics to nursing training.

assess the relationship of respondents across the different geo-political, zones and their attitude towards the introduction of informatics to the nursing training.

\section{Research Questions}

The study answered the following questions.

1. What the demographic variables of the respondents?

2. What is the level of respondents knowledge on the concept of nursing informatics.

3. What are their attitude towards the introduction of informatics to the nursing training.

\section{Research Hypothesis}

There (3) null hypotheses were tested by the study. They were in the null form and tested at 0.05 level of significance. They were:-

1. There is no significant difference in the attitude towards the introduction of informatics to nursing training between male and female respondents.

2. There is no association between the qualifications and attitude of respondents towards the introduction of informatics to the nursing training.

3. There is no association between the respondent from the different geo-political zones and their attitude toward the introduction informatics to the nursing training.

\section{Methodology}

\section{Study Design}

The study adopted a descriptive design. This was done in order to describe the various variables in the study without manipulating any one of them, but to describe them as they occurred in the study.

\section{Research Setting}

The setting was the Osun state of Nigeria with the state capital in Osogbo. It was carried out in April, 2012 during the yearly conference organized by the Nursing and Midwifery Council of Nigeria (N\&MCN) which is the regulating body for all practicing Nurses in Nigeria (Clinical and Education) 


\section{Study Population}

The Study population consisted of directors of nursing services, deputy and assistant directors of nursing, chief and assistant nurse tutors/educators, principal and vice-principal of nursing schools and training institutions $\backslash$ They were two hundred and fifty (250) in number.

\section{Sample size and sampling Technique}

The sample size consisted of one hundred and seventy five (175) respondents. The sampling technique adopted was simple random. The ballot system was used, using the serial numbers on the register for the participants. Out of the one hundred and seventy five (175) respondents selected, only one hundred and fifty (150) returned their questionnaire and they were used for the study.

Research design questionnaire was used to collect data from the respondents. The instrument has three parts as follows:- section A- Demographic Data consisted of 5 items, Section B- Knowledge of Nursing informatics with 7 items and Section C- Attitude towards the introduction of informatics to Nursing training which has 13 items. The questionnaire consisted of both open and closed ended structures questionnaire. The instrument has the correlation coefficient of different

\section{Data Collection Method}

Having received the ethical approval from the deputy Registrar of the Nursing and Midwifery council of Nigeria, the self-design questionnaire was administered by the researchers with the help of two technical staff of NMCN. Individual selected through the simple random technique would be called and the questionnaire would be administered. They were allowed to go with the questionnaire with the instruction that it should be returned a day prior to the closing ceremony. Only one hundred and fifty (150) respondents returned the questionnaire as instructed.

\section{Data Analysis Method}

The research questions were answered using the descriptive analysis in form of frequencies, percentage $\mathrm{s}$ and tables while the three (3) hypotheses were analysed using chi-square and correlation coefficient at 0.05 level of significance with SPSS window 19 version.

\section{Ethical Consideration}

The permission to conduct the study was given by the Nursing and Midwifery lcouncil of Nigeria, the only regulating body for all the practicing nurses. Informed concert was received from individual respondents through documentation.

\section{Limitation}

1. Twenty five (25) of respondents refused to turn-in their own questionnaire as they left before the closing ceremony, hence the questionnaire $\mathrm{c}$ ould not be retrieved from them.

2. This was a descriptive study which demanded for the use of high sample size.

\section{Results}

Table 1- Demographic Data

\begin{tabular}{|l|c|c|}
\hline Variable (Gender) & Frequency(f) & Percent (\%) \\
\hline Gender & & 18 \\
Female & 027 & 82 \\
Total & 123 & 100 \\
Qualifications & 150 & 14.0 \\
RNT & & 49.3 \\
Bsc/BNsc & 21 & 36.0 \\
Msc & 74 & 0.7 \\
Ph.D & 54 & $\mathbf{1 0 0}$ \\
\hline Total & 01 & 06.7 \\
\hline Working Experiences & $\mathbf{1 5 0}$ & 07.3 \\
5-10 years & & 12.0 \\
$11-15$ years & 10 & 44.0 \\
16-20 years & 11 & 30.0 \\
21-25 years & 18 & $\mathbf{1 0 0}$ \\
Above 25 years & 66 & 06.7 \\
\hline Total & 45 & 07.3 \\
\hline Status/Designation & $\mathbf{1 5 0}$ & 12.0 \\
Principal Nurse Tutor & & \\
Assistant Chief Nurse Tutor & 10 & \\
Chief Nurse Tutor & 11 & 18 \\
\hline
\end{tabular}




\begin{tabular}{|l|c|c|}
\hline Assistant Director, Nursing & 66 & 44.0 \\
\hline Total & 45 & 30.0 \\
\hline Status / Designation & $\mathbf{1 5 0}$ & $\mathbf{1 0 0}$ \\
Principal Nurse Tutor & 27 & 18.0 \\
Assistant Chief Nurse Tutor & 24 & 16.0 \\
Chief Nurse Tutor & 34 & 22.7 \\
Assistant Director, Nursing & 35 & 23.3 \\
Deputy Director & 20 & 13.3 \\
Director of Nursing & 10 & 06.7 \\
\hline Total & $\mathbf{1 5 0}$ & $\mathbf{1 0 0}$ \\
\hline Geo-Political Zone & & \\
South-West & 78 & 52.0 \\
South - South & 19 & 12.7 \\
South - East & 18 & 12.0 \\
North - East & 07 & 04.7 \\
North - West & 13 & 08.7 \\
North Central & 15 & 10.0 \\
\hline Total & $\mathbf{1 5 0}$ & $\mathbf{1 0 0}$ \\
\hline
\end{tabular}

With reference to the table1 above, it showed that majority of respondents were females $123(82.0 \%)$ as against 27(18.0\%) male respondents. In terms of qualifications, 74(49.3\%) had B.sc/ BNsc Nursing degree, 54(38.0\%) had masters degree, $21(14.0 \%)$ were with RNT certificates while just $1(0.7 \%)$ was with Ph.dD certificate. The table further showed that $10(6.7 \%)$ of respondents had between 5-10 years of working experience, $66(44.0 \%)$ had between 21-25 years of working experience while 45(30.0\%) had more than 25years working experience. Considering their status/Designation, 27(18.0\%) of respondents were Principal Nurse tutors, 24(16\%) were Assistant Chief of Nurse tutors, 34(22.7\%) were Chief Nurse tutors, 35(23.3\%) were assistant directors of Nursing, 20(13.3\%) were deputy assistant directors while 10(06.7\%) were directors of Nursing. In term of geopolitical spread of the respondents, 78(52\%) were from South-West of Nigeria, 19(12.7\%) were from Southsouth, 18(12\%) were from the South-East, 07(04.7\%) were from the North-East, 13(08.7\%) were from NorthWest, while $15(10 \%)$ were from North-Central of Nigeria. The result showed that there was a good spread of respondents through the geo-political zones constituting Nigeria.

TABLE 2.

KNOWLEDGE ON NURSING INFORMATICS

\begin{tabular}{|c|c|c|c|c|c|c|}
\hline & & \multicolumn{2}{|c|}{ YES } & \multicolumn{2}{|c|}{ NO } & \\
\hline & & Freq & $\%$ & Freq & $\%$ & Total \\
\hline 1. & $\begin{array}{l}\text { Nursing information technology is a concept of caring for } \\
\text { patients by assessing through electronic media. }\end{array}$ & 135 & $90 \%$ & 15 & 10.0 & 150 \\
\hline 3. & It is a new concept in nursing profession. & 92 & 61.3 & 58 & 38.7 & 150 \\
\hline 4. & It has been in use in Nigeria for long time. & 62 & 41.3 & 88 & 58.7 & 150 \\
\hline 6. & $\begin{array}{l}\text { The concept has been in use for the training of the nursing } \\
\text { students }\end{array}$ & 59 & 39.3 & 91 & 60.7 & 150 \\
\hline 7. & The concept is highly technical in usage & 121 & 80.7 & 29 & 19.3 & \\
\hline
\end{tabular}

Considering the table 2, above majority of the responding 135(90.0\%) had knowledge of the concept of informatics while only $15(10 \%)$ were not in training the student nurses, only 59(39.3\%) uses knowledge of information technology in teaching the students while 91(60.7\%) did not use the knowledge of information technology in teaching their students.

TABLE 3. ATTITUDE OF RESPONDENTS TO NURSING INFORMATICS

\begin{tabular}{|c|c|c|c|c|c|c|c|c|c|c|}
\hline & \multirow[t]{2}{*}{ VARIABLE } & \multicolumn{2}{|c|}{ Agree } & \multicolumn{2}{|c|}{$\begin{array}{l}\text { Strongly } \\
\text { agree }\end{array}$} & \multicolumn{2}{|c|}{ Disagree } & \multicolumn{2}{|c|}{$\begin{array}{l}\text { Strongly } \\
\text { disagree }\end{array}$} & \multirow[b]{2}{*}{ Total } \\
\hline & & Freq & $\%$ & Freq & $\%$ & Freq & $\%$ & Freq & $\%$ & \\
\hline 1. & $\begin{array}{l}\text { Introduction of Nursing informatics is an } \\
\text { accepted concept in Nigeria }\end{array}$ & 83 & 55.3 & 57 & 38.0 & 07 & 04.7 & 03 & 02.0 & 150 \\
\hline 2. & It will be cost effective in caring for patients & 65 & 43.3 & 58 & 38.7 & 21 & 140 & 06 & 04.0 & 150 \\
\hline 3. & $\begin{array}{l}\text { It will enhance adequate documentation of } \\
\text { patients records }\end{array}$ & 70 & 46.7 & 72 & 48.0 & 05.0 & 03.3 & 03 & 2.0 & 150 \\
\hline 4. & It will be difficult to operate in Nigeria & 51 & 34.0 & 31 & 20.7 & 62 & 41.3 & 06 & 04.0 & 150 \\
\hline 5. & It will help to improve nursing care & 61 & 40.7 & 82 & 54.7 & 03 & 2.0 & 04 & 02.7 & 150 \\
\hline 6. & $\begin{array}{l}\text { It will allow for easy access to information } \\
\text { on the patients. }\end{array}$ & 76 & 50.7 & 67 & 44.7 & 04 & 02.7 & 03 & 2.0 & 150 \\
\hline 7. & It will embrace team work among health & 80 & 53.3 & 61 & 40.7 & 06 & 04.0 & 03 & 02.0 & 150 \\
\hline
\end{tabular}


Knowledge and Attitude Towards The Introduction of Informatics To Nursing Training Among

\begin{tabular}{|c|c|c|c|c|c|c|c|c|c|c|}
\hline & personnel. & & & & & & & & & \\
\hline 8. & $\begin{array}{l}\text { It will reduce paper work in caring for the } \\
\text { patients. }\end{array}$ & 81 & 54.0 & 65 & 43.3 & 01 & 0.7 & 03 & 2.0 & 150 \\
\hline 9. & $\begin{array}{l}\text { It will encourage comprehensive nursing } \\
\text { care of patients. }\end{array}$ & 75 & 50.0 & 63 & 42.0 & 09 & 06.0 & 03 & 2.0 & 150 \\
\hline 10. & $\begin{array}{l}\text { It will prevent negligence on the nursing } \\
\text { care of parents. }\end{array}$ & 77 & 51.3 & 48 & 32.0 & 22 & 14.7 & 03 & 02.2 & 150 \\
\hline 11. & $\begin{array}{l}\text { It will enhance the maintenance of high } \\
\text { standard of nursing care. }\end{array}$ & 60 & 40.0 & 68 & 45.3 & 12 & 8.0 & 10 & 06.7 & 150 \\
\hline 12. & $\begin{array}{l}\text { Nurse may face threat toward continuity of } \\
\text { their jobs. }\end{array}$ & 23 & 15.3 & 11 & 07.3 & 77 & 51.3 & 39 & 26.0 & 150 \\
\hline 13. & $\begin{array}{l}\text { The advantages derivable from this idea may } \\
\text { not work the efforts. }\end{array}$ & 11 & 07.3 & 07 & 04.7 & 90 & 60.0 & 42 & 28.0 & 150 \\
\hline
\end{tabular}

Considering the table 3 in the above, it was observed that more that half of the respondents $55.3 \%(83)$ supported that the introduction of Nursing informatics into nursing curriculum was a welcome development, $57(38 \%)$ strongly agreed, $7(4.7 \%)$ Disagreed while $3(02.0 \%)$ strongly disagreed. This result showed that when nursing informatics is introduced, it will be accepted by the generality of the tutors and lecturers. On whether its introduction will improve nursing care practice, majority of the respondents $82(54.7 \%)$ strongly agreed that it will improve nursing care while just $3(02.0 \%)$ disagreed and strongly disagree respectively $76(50.7 \%)$ of respondents and $67(44.7 \%)$ agreed and strongly agreed toward the idea that nursing informatics will allow for easy accessibility to information on the nursing care of patients while $3(02,0 \%)$ disagreed. In general the results in table 3 showed that majority of respondents had positive attitude toward the introduction of nursing informatics to the training of student nurses.

Table 4:- Testing of Hypothesis 1 which states "there is no significant difference in the attitude towards introduction of informatics to nursing training between Male and female respondents"

INTRODUCTION OF NURSING INFROMATICS IS AN ACEPTED CONCEPT IN NIGERIA

\begin{tabular}{|l|l|l|l|l|l|}
\hline Gender & Agree & Strongly Agree & Disagree & Strongly Disagree & Total \\
\hline Male & 11 & 16 & 0 & 0 & 27 \\
\hline Female & 72 & 41 & 07 & 03 & 123 \\
\hline Total & 83 & 41 & 07 & 03 & 150 \\
\hline
\end{tabular}

$\mathrm{X} 2=\mathrm{X} 2 \mathrm{cal}=0.061, \mathrm{X} 2 \mathrm{tab}=7.378, \mathrm{df}=3, \mathrm{P}=0.05$

Considering the table 4 above, the table value (7.378) is greater than the calculated value $(0.061)$ at 0.05 level of signature, it implies that there was no significant difference in the attitude towards introduction of nursing informatics to nursing training between male and female respondent. Therefore the null hypothesis was accepted.

Table5. Testing of hypothesis to which "there is no association between the qualification and attitude of respondent towards the introduction of informatics to nursing training. (Correlation)

\begin{tabular}{|l|l|c|c|}
\hline \multicolumn{2}{|c|}{ Spearman's rho } & Qualifications & $\begin{array}{l}\text { It will embrace team work } \\
\text { among health personnel }\end{array}$ \\
\hline Qualifications & $\begin{array}{l}\text { Correlation coefficient } \\
\text { sig (2-failed) N }\end{array}$ & 1.000 & -105 \\
Correlation - coefficient & 150 & .203 \\
$\begin{array}{l}\text { It will embrace team work among } \\
\text { health personnel. }\end{array}$ & sig. (2 failed) N & -.105 & 150 \\
& & .203 & 1.000 \\
& & 150 & 150 \\
\hline
\end{tabular}

Table 5 above showed that correction coefficient $(-0.105)$ was negative, this implies that there was no association between the qualification and attitude of respondents towards the introduction of informatics to nursing training.

Table 6. Testing of hypothesis 3. It states "there is no association between the respondents from the different geo-political zones and their attitude towards the introduction of informatics to nursing training. 


\begin{tabular}{|c|c|c|c|c|}
\hline \multicolumn{5}{|c|}{ Correlation } \\
\hline & & Geo Political Zones & $\begin{array}{l}\text { It will } \\
\text { of pati }\end{array}$ & $\begin{array}{l}\text { e adequate documentation } \\
\text { cords. }\end{array}$ \\
\hline \multirow{3}{*}{ Spearman's rho } & \multirow{3}{*}{$\begin{array}{l}\text { Geo-Political Zones } \\
\text { It will enhance adequate } \\
\text { Documentation of patients } \\
\text { records }\end{array}$} & \multirow{3}{*}{$\begin{array}{l}\text { Correlation-coefficient } \\
\text { Sig. (2-tailed) } \\
\quad \text { N } \\
\text { Correlation- } \\
\text { Coefficient } \\
\text { Sig. (2-tailed) } \\
\quad \text { N }\end{array}$} & 1.000 & .135 \\
\hline & & & 150 & $\begin{array}{r}.099 \\
150\end{array}$ \\
\hline & & & $\begin{array}{l}.135 \\
.099 \\
150\end{array}$ & $\begin{array}{c}1.000 \\
150\end{array}$ \\
\hline
\end{tabular}

Considering the table 6 above, the correlation coefficient was positive (0.135), the implies that there is association between the respondent from different geopolitical zones and their attitude towards the introduction of informatics to nursing training.

\section{Discussion of Findings:}

Can the demographic data, majority of respondents were females $123(82 \%)$ while only $27(18 \%)$ were females. This showed that the nursing profession in Nigeria is still being dominated by women folks in terms of qualification higher percentage of respondents had first degree (Bsc/BNSc) in Nursing 74(49.3), while 54(36.0\%) had Masters degree and only 1(0.78) had Ph.d. This showed that the training of nurses in Nigeria remained the priviledge of only BNCs degree holders. Table 1 showed that all the tutors were experienced in their chosen field. In term of geopolitical spread, all the different zones in the country (Nigeria) were represented, 78 (52\%) from SouthWest, 19(12.7\%) from South/South, 78(12\%) from South/East, 07(04.7\%) from North/East, 13(08.7\%) from North/West and 15(10.\%) from North Central. In terms of Awareness of Nursing Informatics, table 2 showed that majority of respondents \& $135(90 \%)$ were aware of the concept of nursing informatics while only $15(10 \%)$ were not aware ${ }^{5,6,7}$. Regarding the attitude respondent to the introduction of Nursing informatics to nursing training, high percentage of respondents (83) $55.3 \%$ affirmed that its introduction to nursing curriculum was welcome development while $3(02.0 \%)$ strongly disagreed ${ }^{3,4,5,6,7}$. This showed that the introduction of Nursing informatics was a welcome idea by the generality of Nurse tutors and lecturers in Nigeria. On whether the introduction of Nursing informatics will improve the nursing care practice $61(40.7 \%)$ of respondents agreed with this item, $82(54.7 \%)$ strongly agreed, $3(20 \%)$ disagreed while $4(2.7 \%)$ strongly disagreed to the ability of nursing informatics to improve the nursing practice $e^{3,4,5,9,10} .76(50.7 \%)$ of respondents affirmed that nursing informatics will allow for easy accessibility to information on nursing care of a patient, while $67(44.7 \%)$ strongly agreed, only $(2.7 \%)$ and $3(2.0 \%)$ disagreed and strongly disagreed respectively. This finding depicted that the selected nurses were aware of the importance of information toward caring for their patients. ${ }^{10,16,17,18,19}$ on the cost effectiveness of informatics to patient care, $65(43.3 \%)$ of respondents agreed that it would be cost effective, 58(38.7\%) strongly agreed, 21(14.0\%) disagreed while $6(4.0 \%)$ strongly disagree. This finding showed that nurses showed positive attitude toward the cost effectiveness of nursing informatics ${ }^{5}$. On its difficulty nature in Nigeria, the finding shared that $51 \%(34.0 \%)$ affirmed its difficulty nature, 31(20.7) strongly agreed with the items $62(41.5 \%)$ disagreed while just $6(4.0 \%)$ strongly disagreed. This finding showed that higher percentage did not subscribed to the attitude that nursing informatics was difficult ${ }^{5.10}$. Table 4 that assessed if there is significant difference in the attitude towards the introduction of informatics to nursing between male and female respondents. The finding showed $\left(\mathrm{X}^{2} \mathrm{cal}-\right.$ $0.061, X^{2}$ table $=7.378, \mathrm{df} .3, \mathrm{P}=0.05$.) that the table value (7.378) was greater than the calculated value $(0.061)$ at 0.05 level of significance, this depicted that there was no significant difference in the attitude towards the introduction of informatics to nursing training between male and female respondents. This finding showed that gender would not be a barrier towards the introduction of informatics to the nursing practice in Nigeria, however, non of literature reviewed had gone into this part of this finding. In determining whether there is any association between the qualifications and attitude of respondents towards the introduction of informatics to nursing, table 5 showed that the correlation coefficient was negative $(-0.105)$, it implies that there was no association between the qualification and attitude of respondents towards the introduction of informatics to the nursing training. This showed that qualifications would not be a barrier towards introducing of nursing informatics to the nursing practice5.7,8. Can the attitude of respondents across the geo-political zones towards the introduction of informatics to nursing training. Table 6 showed that correlation coefficient was positive $(0.135)$. This showed there was association between the respondents within different geopolitical zones and their attitude towards the introduction of informatics to nursing training. This finding in essence, depicts that the introduction of nursing informatics into the curriculum may not commence at the same time. The attitude toward the introduction of informatics to nursing varies in difference geopolitical zones. This was in line with a study students and nursing students on the use of information technology $\mathrm{y}^{6,8}$. 


\section{Conclusion}

It has been established introduction of informatics to nursing training is a welcome development, therefore the national universities commission should ensure the enforcement of implementing it in the training of nursing students in the universities that are training nurses in Nigeria, at least it is in the bench mark of the NUC. In the same vain, the Nursing and Midwifery Council of Nigeria should ensure the implementation of the bench mark on the training the graduate nurses.

\section{Recommendation}

All the institutions training Nurses whether the hospital based or university base must ensure that the NUC and NIMCN Curriculum on Nursing informatics is adequately implemented.

Irrespective of nature of training and education all nursing students must be made to have a computer with internet facilities so that they would have develop competence before graduating from their institution, the knowledge acquired can then be used in their nursing care.

For further study, the study should be replicated by using large number of respondents, and the level of the utilization of ICT in nursing care.

\section{Acknowledgement}

We acknowledged the permission granted by the Nursing and Midwifery Council of Nigeria to use its perticipants at the workshop, equally we thank our assistants for painstakingly seeing to the retrieval of the questionnaires.

\section{References}

[1]. Anna, D Effihia G, Dimos M, Maria N. Undergraduate Nursing Students' Computers skills assessment: a study in Greece. Health Science Journal 2010; 4(3), 182-188.

[2]. Myers MR. Telemedicine an emerging health care technology. Health Care Mang. 2003, 22(3): 219-233

[3]. Edworthy sm. Telemedicine in developing countries. BMJ 2001 Sep 8; 323 (7312): 524-525.

[4]. Ogunyade T.O, Oyibo WA. Use of CD or CD-ROM MEDLINE by medical students of the College of Medicine, University of Lagos, Nigeria. Med Internet Ros Mar 31;5(1).

[5]. Aarons, G.A. Mental health provider attitudes toward adoption of evidence-based practice: the evidence-based attitude scale (EBPAS). Mental Health Service Research 6(2), 61-74.

[6]. Marita, K., Maritta V., Heli, H. Nurses' Information retrieval skills in psychiatric hospitals - Are the requirements - for evidencebased practiced fulfilled, Nurse Education in Practice 10(2010), 27-31. www.elsevier.com/nepr assessed 14-08-13.

[7]. Griffiths P, Riddingfon L. Nurses use of Computer databases to identify evidence for practice a cross-sectional questionnaire Survey in a UK hospital. Health info Libr J. 2001; 19(1): 2-9.

[8]. Austin SI. Baccalaureate nursing fealty performance of nursing computer literacy skills curriculum integration of these through teaching practice. J. Nursing Educ 1999; 38(6): 260-6.

[9]. Alexander B. Going Normadic: Mobile learning in Higher Education EDUCAUSE Review 2004; 39(5), $28-35$.

[10]. Retsas, A. Barriers to using research evidence in nursing practice. Journal of Advanced Nursing, 2000 31(3), $599-605$.

[11]. Mcsherry, R, Arthley, A; Holloran, J. Research Awareness. An important factor for evidence - based practice? World views of Evidence-Based Nursing, 2006. 3(3), 103-115.

[12]. MoH, B. Nolan, J, Zard, et al. Clinical nurses knowledge of evidence-based practice: Constructing a framework to evaluate a multi faceted intervention for implementing EPB. Contemporary Nurse, 2005; 19(1-2) 96-104.

[13]. Paramonczic A. Barriers to implementing research in clinical practice. Canadan Nurse, 2005. 101(3), 12-15.

[14]. Hannes, K Vandersmitten J, De Bluesser G. et al. Barriers to evidence-based nursing: a focus group study. Journal of Advanced Nursing, 2007, 60(2); 162-171

[15]. Jutel, A. Beyond evidence-based nursing: tools for practice, Jounal of Nursing Management, 2008. 16(4), $417-421$.

[16]. Chastain, AR. Are nursing faculty members ready to integrate information technology into the curriculum? Nursing Education Perspective 202. 23(4); 187-190.

[17]. Webster J, Davis J, Hotl V, et al. Australian nurses and midwives' knowledge of computers and their attitude to using them in their practice. Journal of Advanced Nursing, 2003, 41(2); 140-146.

[18]. Wilbright WA, Haun DE, Krutzfeldt T. Computer use in an urban university hospital. Computers, informatics, Nursing, 2006; 24(1), 37-43.

[19]. Koivunen M, Valimaki M, Koskinen. A et al. The impact of individual factors on health care staff's computer in Psychiatric hospitals journal of clinical Nursing 2009 18(8), 1141-1150.

[20]. Chastain AR. Are nursing faculty members ready to integrate information technology into the curriculum? Nursing Edcuation Perspectives 23(4) 187-190. 